\title{
Navigating the complexity of the therapeutic and clinical use of photography in psychosocial settings: a review of the literature
}

\author{
Emanuela Saita, Martina Tramontano \\ Department of Psychology, Catholic University of Sacred Hearth, Milan, Italy
}

\begin{abstract}
In contrast with the recent increase in the use of photography as a therapeutic tool in psychological settings, lack of clarity exists regarding this intervention modality. While the distinction among Photo Therapy, Therapeutic Photography, and Photo Art Therapy is theoretically established we examined whether this classification is confirmed also in practice. Electronic databases (PsychINFO, PubMed, MEDLINE, and Social Sciences Abstracts-EBSCO) were systematically searched for studies published in the last fifteen years utilizing photographic techniques as the elective method of intervention. A total of 124 articles were identified, of which 21 met the inclusion criteria. Results indicate that photography has been used in health, clinical, social, and community settings. Photovoice, Photographic Self-Portrait, and Photo Presentation are the methods most commonly implemented. Several contributions could be placed in more than one of the above-mentioned models of intervention; suggesting that the criteria to assign articles to each model are difficult to apply when the models are put into practice.
\end{abstract}

Key words: Literature review; Phototherapy; Therapeutic photography; Photo art therapy; Psychosocial settings.

\section{Introduction}

The application of photographs in clinical and therapeutic contexts has grown significantly in recent years (Loewenthal, 2013). The beginning of therapeutic use of photos is identified in the middle of the $19^{\text {th }}$ century, when Hugh Diamond (a medical doctor) conducted the first therapeutic intervention with photographs, which is presented in his 1856 article On the application of phototherapy to the physiognomic and mental phenomena of

Correspondence: Emanuela Saita, Department of Psychology, Catholic University of Milan, Largo A. Gemelli 1, Milano, 20123, Italy. Tel.: +39.0272342688.

E-mail: emanuela.saita@unicatt.it

Acknowledgments: the authors would like to thank Prof. Chiara Acquati for her comments and feedback on the earlier versions of this manuscript.

Conflict of interest: the authors declare no potential conflict of interest.

Funding: none.

Received for publication: 29 November 2017.

Revision received: 18 January 2018.

Accepted for publication: 20 January 2018.

This work is licensed under a Creative Commons Attribution NonCommercial 4.0 License (CC BY-NC 4.0).

CCopyright E. Saita, 2018

Licensee PAGEPress, Italy

Research in Psychotherapy:

Psychopathology, Process and Outcome 2018; 21:1-11

doi:10.4081/ripppo.2018.293 insanity. Similarly to paintings or other artistic techniques, photos can be applied to the clinical intervention with individuals and groups. From the beginning of the last century to the 1970 s, several attempts to apply photography in clinical contexts have been registered. These initial works focused especially on the cathartic power of the image. Between 1980s and 1990s, authors started to systematically classify the different purposes of using photos to promote mental health. Finally, since the last decades of the past century the research has been aimed at categorizing the clinical use of photography, with the identification of different models and methods of intervention (an overview of the historical development is available in Stewart, 1983). In other words a different way of using photos: a modus operandi (a model) and what, when, and why a therapist uses some techniques (a method); about the classification of techniques, see Weiser, 1999.

According to Halkola, photography in clinical and therapeutic settings is mainly aimed to facilitate the individual's ability to recognize and express emotions, thus promoting self-understanding (Halkola, 2009). This intervention modality is often called Photo Therapy (Halkola, 2013). However, this term is used in the literature to address a great variety of programs, often very different from each other and where the photographic stimulus is introduced for dissimilar purposes (Loewenthal, 2009). At the same time, the different legal requirements about the therapeutic activity and different kinds of licensure to practice psychotherapy among countries complicate the definition of Photo Therapy (Weiser, 1993; 1999). This approach was initially introduced in the psychological sciences in the 70's when pioneers like Entin (1981), Krauss (1979), Stewart (1979), Weiser (1975; 1983), Walker (1982; 1983), and 
Wolf $(1976$; 1978) started to explore the potential of photography in promoting communication, self-growth, and healing. A second category of intervention models is referred to as Therapeutic Photography (Loewenthal, 2013). Then, at the International Symposium of Photo Therapy and Therapeutic Photography in 2008 it was proclaimed the formalization of a third category: Photo Art Therapy. For a review of the debate occurred during that meeting, it's possible to refer to Phototheraphy and Therapeutic Photography, 2009.

Hence, it is necessary to consider the distinction among models of intervention, while also being cautious of the fact that these definitions differ extensively in the literature and among countries (Weiser \& Krauss, 2009). Photo Therapy refers to the use of photography and personal snapshots during therapy, where trained professionals use these methods to help clients during the counseling session. Therapeutic Photography is used to address photo-based activities that are self-initiated and conducted by the individual (or as part of an organized group or project), but where no formal psychotherapy is taking place. Finally, Photo Art Therapy includes photographic techniques, which can involve the practical use of Art Therapy. The American Art Therapy Association defines Art Therapy as an integrative mental health profession that combines knowledge and understanding of human mind and the psychological theories and techniques with visual arts and the creative process to provide a unique approach to help patients improve the psychological health, the cognitive abilities, and the sensory motor functions (American Art Therapy Association, 2016). Photo Art Therapy is based on the idea that verbal narratives of produced photos can contribute to the development of interpersonal skills, manage behavior, and increase self-esteem and self-awareness. Weiser (2004) undelines how Photo Art Therapy is a modality of Photo Therapy utilized by art therapists and expressive art therapists trained in art media and creative processes, so that the creation of artwork is involved in the meeting with the client.

While this distinction is theoretically established and clear, the authors were interested in examining whether this classification is confirmed also in practice settings. Hence, this review is aimed at investigating i) in which contexts photography is used and which are the goals authors identify for their work; ii) which specific methods are utilized; iii) the models of intervention used and if they adhere to the abovementioned classification; and iv) who are the professional figures who deliver these arrays of interventions. Given the increasing attention for this topic, as evidenced by the publication of several systematic reviews in recent years (DeCoster \& Dickerson, 2014) the present literature review focuses on the contributions published in the last fifteen years with the goal to offer the reader a comprehensive, although heterogeneous, overview of the application of techniques, within a variety of contexts and aims. Main goals of using photography as well as a description of the key context of application will be analyzed in the last part of this paper.

\section{Search strategy and Studies selection}

To ensure rigour, this review adhered to the Preferred Reporting Items for Systematic Reviews and Meta-Analyses (PRISMA) Statement (Moher et al., 2009; Shamseer et al., 2015). Electronic databases (PsychINFO, PubMed, MEDLINE, and Social Sciences Abstracts-EBSCO) were searched using a combination of key terms (photo therapy, therapeutic photography, photo art therapy) in the abstracts using the Boolean operators and/or. The search was limited to quantitative and qualitative studies published in peer-reviewed journals from January 2000 to April 2016 (This range of years was chosen because in 1999 Judy Weiser had published an important article quoted in our review - with the aim of providing a first systematized classification of phototherapy techniques). To be eligible, manuscripts had to meet the following criteria: i) utilize photographs as the elective method to conduct interventions in clinical and therapeutic settings; and ii) being written in English. Materials lacking original data (i.e. summaries of work, systematic reviews, and conference proceedings) and dissertations were excluded.

The search yielded 124 articles. After having removed the duplicate records, the investigators independently reviewed the records (title and abstract) of 96 articles originally identified and excluded 18 articles, according to eligibility criteria. The remaining 78 articles were reviewed in their entirety. Fifty-seven were excluded for the following reasons: use of other languages, being a congress report, use of tools other than photographs, medical use of photo therapy, psychological outcomes not reported, being chapters, systematic reviews, and editorial and commentaries. Twenty-one studies were included in the review. Figure 1 shows the flow of the study identification process, retrieval, and the number of eligible articles.

\section{Results}

\section{Qualitative synthesis of the articles}

The two authors, at first independently, have classified the articles included in the literature review, then the discrepancies were discussed to reach an agreement; a third investigator resolved discrepancies identified when the two coders did not agree about the classification of the studies in the categories examined. The classification has been made according to 4 criteria: i) the context, which is the setting of application; ii) the photographic methods used; iii) the model of intervention; and iv) the professional figure who delivered the intervention. Table 1 summarizes information extracted from each study, according to the aims of the present manuscript.

\section{Where? Contexts of application}

Three are the main contexts where the articles included 
in the review have been applied: health settings ( 9 articles), clinical settings (6 articles), and social and community settings (6 articles). Social and community settings label refers to a group of individuals who identify themselves as a unity from a cultural, social, and/or political viewpoint - i.e. the study conducted by Prag \& Vogel (2013).

\section{Health settings}

Articles belonging to this first category included both preventive and therapeutic experiences, which focused on cognitive and emotional well-being. For example, Graham,
Stockinger and Leder (2013) applied the use of images with individuals affected by Alzheimer disease (AD), in particular those who were characterized by severe impairment in their cognitive abilities. The investigators wanted to explore the esthetic perception (defined as a cognitive function enabling esthetic judgments of images, paintings or photos) of individuals affected by the disease, by comparing them to a group of healthy older adults. An aspect of novelty is represented by the attention paid by the authors to a variety of image contents (which included painted and photographic portraits, as well as painted and photographic land-
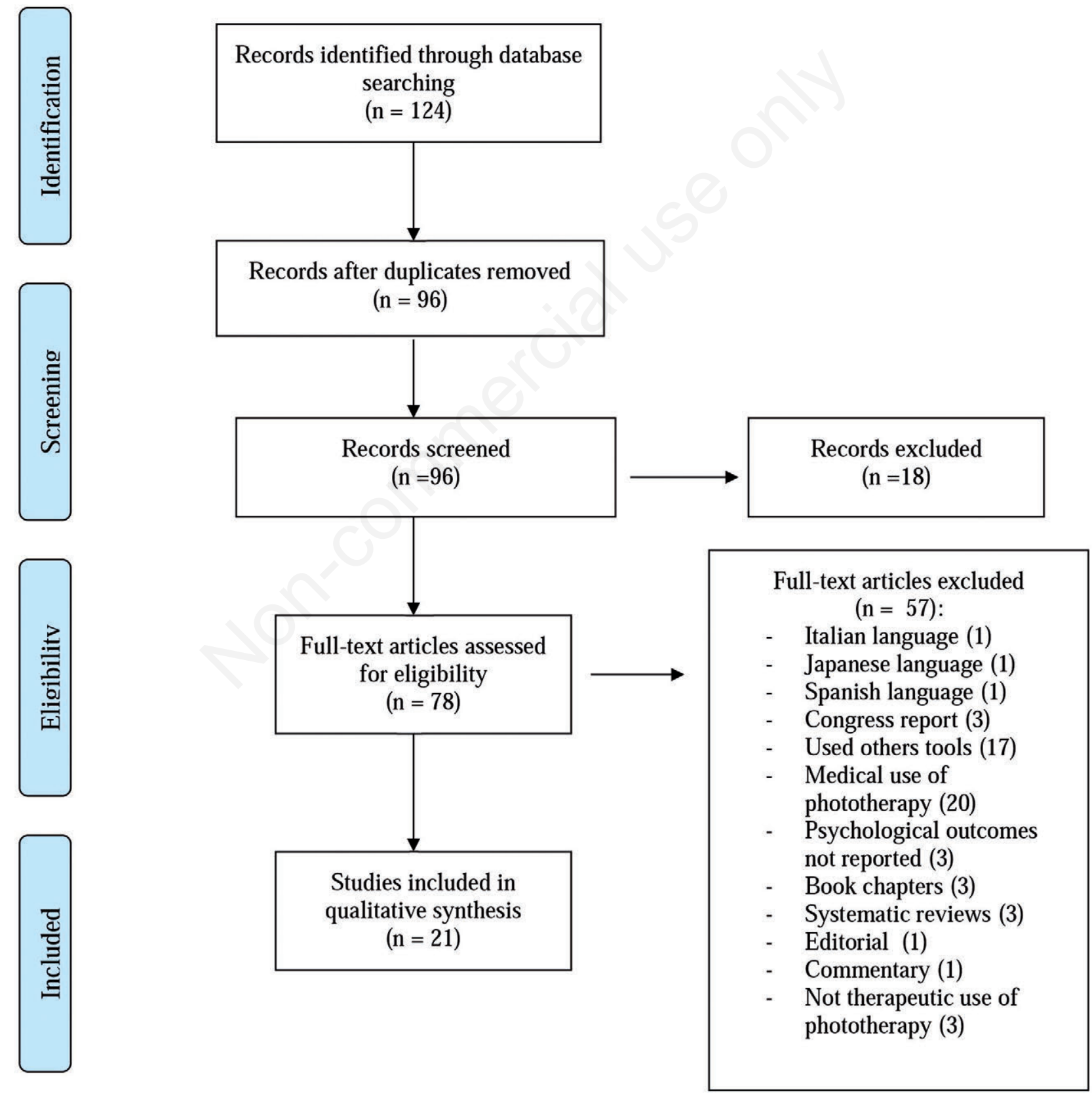

Figure 1. PRISMA flowchart of the studies' selection process. 


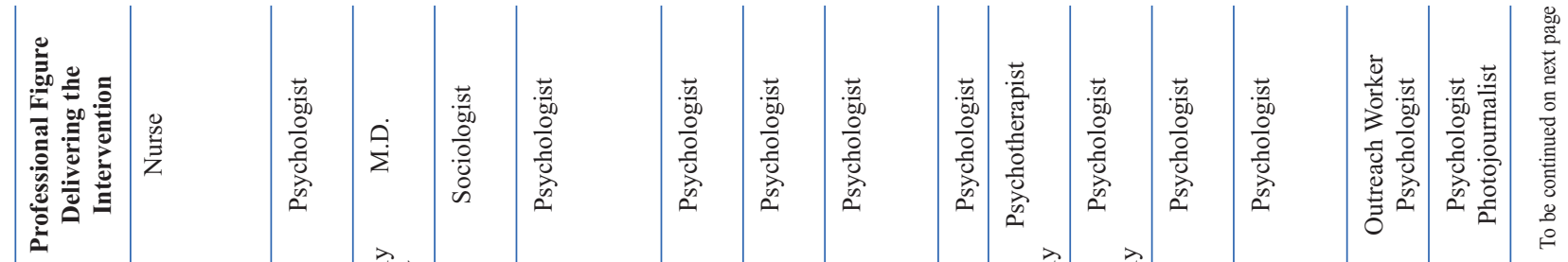

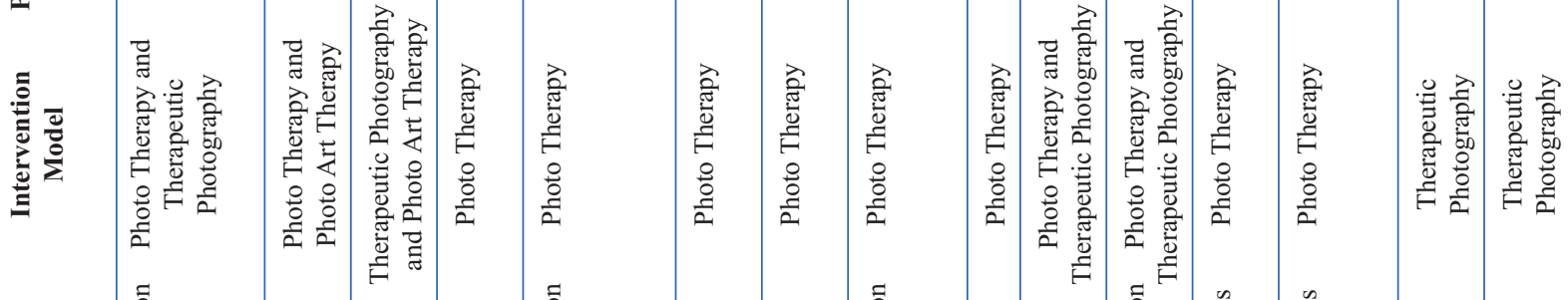

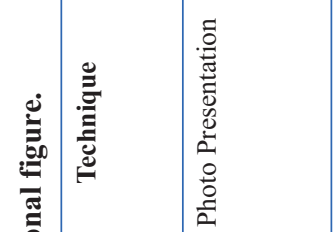

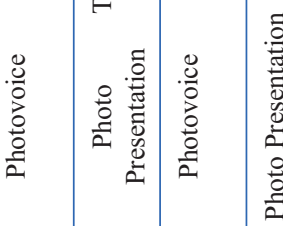

를

竞

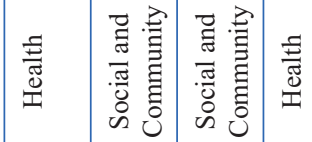

: ن

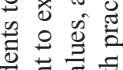

在

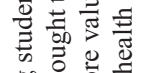

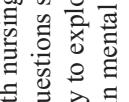

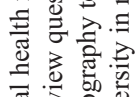

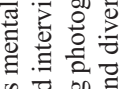

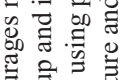

言总言

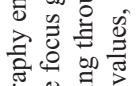

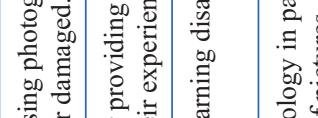

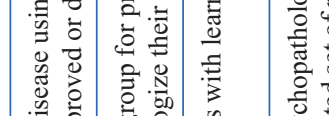

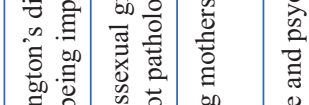

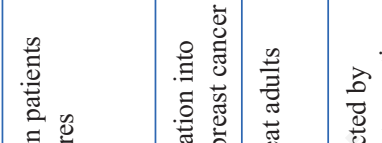

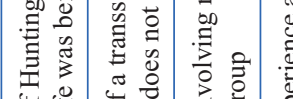

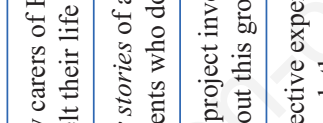

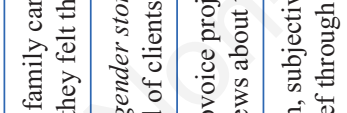

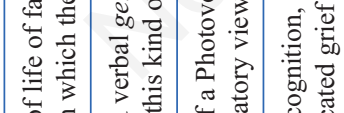

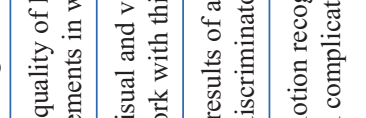

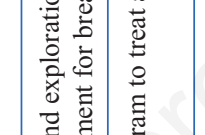

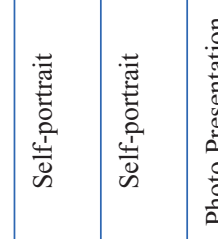

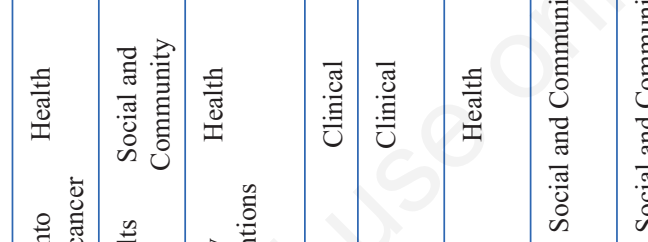

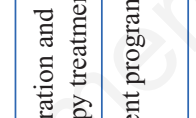

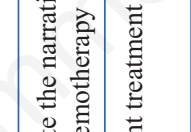

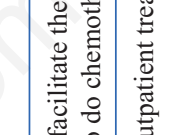

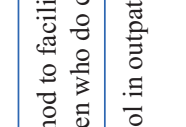

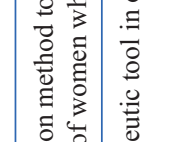

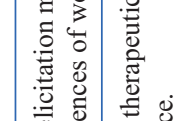

:

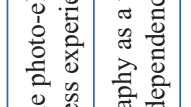

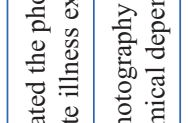

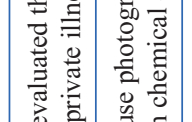

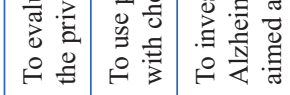

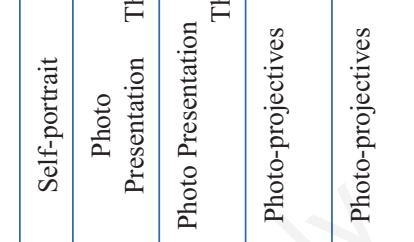

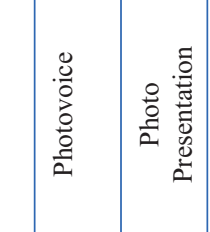

密

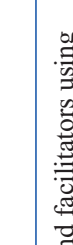

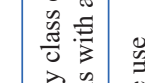

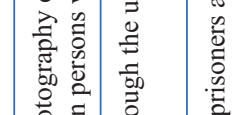

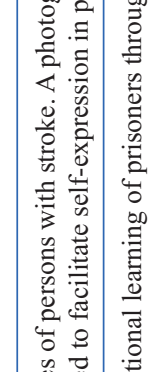

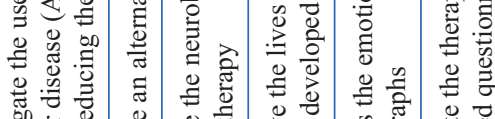

黄 


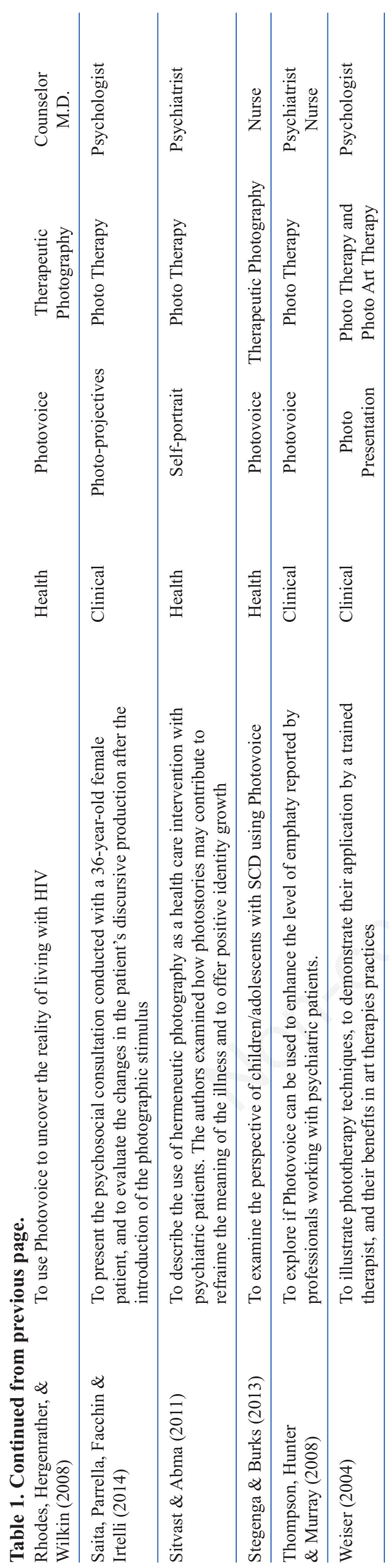

scapes). Four sets of eight images were used as stimuli and participants were asked to rank-order them according to their esthetic preference. Two weeks later, six pairs of images were shown (comprising old images plus distracter images) and participants were asked to indicate which of the images they had seen. The results highlight that individuals with $\mathrm{AD}$ present the same estethic ability as the control group for all the paintings and photographs, with the exception of photographs of faces; suggesting that for individuals with $\mathrm{AD}$, esthetic perception of image represents an element of stability in a condition that causes cognitive disruption (Graham, Stockinger, \& Leder, 2013).

If we consider the emotional dimension, photographs were utilized to explore the personal experience of individuals diagnosed with chronic illnesses, or as a medium to express emotions and feelings. Some studies included in this category have highlighted how the photographic stimulus enables patients to voice physical and psychosocial challenges, especially when the participants are children and adolescents. This is well represented by a research study aimed at examining the unique life perspective of children and adolescents diagnosed with Sickle Cell Diseases (SCD), which causes significant impairments on the physical and psychological well-being. Specifically, among the pediatric population the disease negatively affects social functioning and peer relationships, with long-term risks for psychological well-being, academic achievement, and quality of life. Stegenga and Burks (2013) conducted a pilot study using Photovoice - a form of participatory action research we will describe in further detail later in the article - on a sample of 12 participants between the ages of 6 and 14 who were attending a summer camp organized for SCD patients and their siblings. The study has shown how the use of photographs contributed to access the emotional experience of younger patients with SDC, highlithing the relevance friends, symptoms management, and the camp had for them (Stegenga \& Burks, 2013).

The literature also suggested that photographic methods can be utilized to enhance the ability to express emotions with individuals who experience functional impairments because of chronic illnesses like neurological diseases, cancers, and amyotrophic lateral sclerosis (ALS). We refer here to the study conducted by Levin, Scott, Borders, Hart, and Lee (2007) on subjects experiencing motor difficulties and limited movements as a consequence of a stroke. The limits created by aphasia, and the following verbal and motor impairments, were reduced by the experience of participating in Aphasia Talks, a five-week curriculum inspired by Photovoice, which promoted the use of photographs as a channel to communicate feelings and emotions (Levin et al., 2007).

\section{Clinical settings}

The second context is exemplified by clinical settings, which represent the application of photography in the therapeutic experience of individuals affected by mental disor- 
ders. These contributions ( 6 articles) described how photos can facilitate the process of accessing the emotional dimension and improve self-awareness among participants. An example can be found in the utilization of images in the therapeutic process, as described by Pickin, Brunsden and Hill (2011). They have investigated the subjective experience of foster carers. Participants were asked to take photographs, which symbolized their emotional experience, and these products were later used as a starting point for an interview with members of the research team. The combined use of Photovoice and interpretative phenomenological analysis contributed to the exploration of the participants' emotional experience, often allowing for deeper and greater insights. A wide range of emotions and challenges were identified, thefore supporting the use of verbal and non-verbal strategies to access methaphorical representations of the individual (Pickin et al., 2011, p. 71).

\section{Social and community settings}

Finally, social and community goals - social and community goals indicate function of photographic method to improve condition within context that had positive social ripercussions. Infact the goal of this group of articles is connected with thematic like social exclusion, humanitarian effort, identity of minority group and such as - characterized the third type of setting ( 6 articles). The distinctive aspect of this group of articles is that the photographic method is used with the purpose to reduce social exclusion. In particular, psychosocial interventions were developed for individuals belonging to minority groups (i.e. sexual minority groups, war refugees, incarcerated populations, and low income individuals) with the goal to increase awareness of their life experiences. Some studies (3 articles: Barbee, 2002; Booth \& Booth, 2003; Glover Graaf \& Miller, 2006) used pictures to explore issues connected with identity, both at the individual and group level.

Among the experiences listed in this category, a study was conducted within the humanitarian aid context. Specifically, Prag and Vogel (2013) have applied a form of therapeutic photography with Shan adolescent refugees in Thailand to promote the verbalization of traumatic memories, and to integrate their traumatic past in their life-story. For the purpose of this review, the study is particularly meaningful as it was aimed at examining the potential of therapeutic photographs to promote the association between visual awareness and self-awareness (Prag \& Vogel, 2013).

Finally, the two remaining contributions elucidated the use of photography within the criminal justice system. The article authored by Loewenthal (2015) described three different approaches (Talking Pictures Therapy, Talking Pictures Books, and Photo-assisted Rehabilitation) developed to enhance emotional intelligence in the incarcerated population. Preliminary findings suggest that the use of photographic techniques with prison population is a potentially beneficial approach because photos repre- sented a non-verbal communication, which can help prisoners in emotional expression and sharing, in a context characterized by limited opportunities, where trust is fragile. All three of these techniques have shown that the clinical use of photography appears to be applicable for the criminal justice system, as it contributes to overcome barriers associated with verbal expression, thus facilitating the work with non-native speakers or individuals from a low socio-economic background.

\section{How? The photographic methods}

The photographic methods used in the articles included can be summarized in Photovoice (6 articles), Photographic Self-Portrait (4 articles), and Photo Presentation (11 articles of which 3 were photo-projectives).

\section{Photovoice}

Photovoice is a method aimed at identifying the needs of a community or social group and motivating social change. Individuals are active participants, supported through discussion- to identify their point of view, then represented by their photo shoots. Finally the subjects, under the guidance of a professional, make a photography exhibit to show their work.

This new self-awareness is used to promote changes through the influence of images on politicians and local stakeholders (Wang \& Burris, 1994). Contributions using Photovoice can be placed in the health promotion context (3 articles: Rhodes et al., 2008; Aubeeluck, \& Buchanan, 2006; Stegenga \& Burks, 2013) and have been aimed at sensibilizing and changing the opinion of the people of a society or a community on the issues associated with diseases, and the need to engage them in preventive strategies to reduce the incidence of illnesses ( 2 articles). Leading actors of the experience are the individuals, who become the narrator of their life experience with the disease and agents of change to contribute to a greater understanding and awareness of the illness in their social context. The experience of indigent individuals living with HIV in the South of the United States has been the focus of attention of the investigation by Rhodes, Hergenrather, Wilkin, and Jolly (2008). The authors conducted an exploratory study to highlight and gain understanding of the life experiences of individuals living with HIV by inviting the participants to complete a photo assignment, which was followed by the discussion of six photos. The ultimate goal was to organize a locally funded exhibition to address the misinformation and the stigma associated with HIV (Rhodes et al., 2008). A second article has focused on the experience of spousal caregivers of individuals affected by Huntington's disease, to describe their experiences and to highlight issues associated with caregiving issues. Carers were asked to take photographs of objects representing an aspect of compromise or an improvement in their quality of life, and to elaborate about the meanings the photographs conveyed. Through the use 
of Photovoice and content analysis, the investigators identified how partners' quality of life was negatively influenced by the disease and the experience of providing care for their loved ones (Aubeeluck, \& Buchanan, 2006).

Two articles have applied this method in clinical settings (Pickin, Brunsden \& Hill, 2011; Thompson, Hunter \& Murray, 2008) and have been aimed at exploring the emotional experience of individuals affected by psychiatric disorders and that of foster parents. Thompson, Hunter and Murray (2008) conducted a qualitative study involving 7 adult patients with chronic mental illness (one of the inclusion criteria required participants to have been in psychiatric treatment for more than 2 years). Authors asked each participant to select 4 , among all of their pictures, to be discussed during the interview and to explain the meaning these pictures had illustrating their experience as individuals with psychiatric disorders. The technique ehnanced the participants' sense of value and shed light on the unspoken suffering which accompanies their lives, as they feel isolated not only by health professionals but by their own family members as well.

Among the experiences focusing on social and community well-being, only one article has implemented Photovoice. We refer to the contribution Booth and Booth (2003) have dedicated to mothers with learning difficulties. In this case, the aim of the study was twofold: to contribute to the Supported Learning Project attended by the women, and to challenge discriminatory views. Their work described what was important for these women, as their photo albums demonstrate the primacy of children, place and the significance of friends. However, the resulting photos also revealed the lack of support from partners, relatives, and services (Booth \& Booth, 2003).

\section{Self-portrait}

Self-portrait has a longstanding and complex origin, as the myths of Narcissus and Dionysus already exemplified the need of men to represent themselves. This need suggests the central role self-image has in building and stabilizing one's identity as well underlined by Spence's work (1986).

The photographic self-portrait hence gives the individual the possibility to shape his image according to his needs and desires, introducing the opportunity of self-reflection (Nuñez, 2009). The countributions (4 articles) included in the current work use this technique with a diverse array of goals.

Within the context of health, two articles applied selfportrait to facilitate the elaboration of the illness experience, especially about self-perception. An example is the work of Frith and Harcourt (2007) who have used photoelicitation to facilitate the narratives of women receiving chemotherapy treatment for breast cancer. Self-portraits (realized during the cancer treatment and subsequently dicussed in an interview at the end of the active treatment phase. It is important to clarify that the self-portrait tech- nique includes alternatives for those subjects who experience difficulties in the process. When this happens, participants are given the possibility to choose images that describe themselves and their self-perception) have been used to promote women's self-reflection and their feeling of taking control over a changing body image; thus contributing to their ability to adjust to the cancer experience (Frith \& Harcourt, 2007).

In clinical settings, the only experience included in our search pertains to the use of self-portrait with depressed individuals. In the contribution by Hanieh and Walker (2007) participants were asked to make 12 photographs to answer the question Who are you? and their products were compared to a not depressed control group. Results indicated that photography represents an alternative measure of previous indicators of constriction; especially because of the advantages associated with it (it was perceived as an nonthreatening, and enjoyable experience). Assessing the elements of Self and Future Self (how you see yourself at present $e$ in the future), the data underlines as depressed individuals were more likely to report difficulties in establishing their Sense of Self in the present and also to build a Future Self. Similarly, the photographic measure revealed that depressed individuals exhibited a reduced range of themes in their pictures, documenting a smaller number of objects, events, and activities when compared to the control group, suggesting that individuals with depression may experience stronger boundaries of their perceptual field and limited interaction with the environment (Hanieh \& Walker, 2007); an indication that only the nonverbal approach could convene to the team.

To the social and community setting group belongs the study by Glover Graf and Miller (2006) with chemically dependent individuals and aimed at increasing self-esteem and self-efficacy. Pre and post-test administration of validated questionnaires about trauma symptoms, abuse, and self-esteem contributed to the identification of individual growth as a consequence of the photographic experience (Glover Graf \& Miller, 2006).

\section{Photo-presentation}

Eleven articles use this method and they are characterized by great heterogeneity.

Photo Presentation involves the use of sets of images or pictures chosen by the same individual. After the presentation of the images, a clinical interview or a discussion takes place.

Some articles included in this review can be placed in the clinical context (2 articles: Karlsson, 2013; Weiser, 2014) and illustrate the facilitating role of the photographic instrument during psychotherapy or counseling. Some authors have discussed the psychotherapeutic function of photography, thus elaborating on the fact that photographs provide people new tools to understand their life experiences. 
Empirical studies in the context of health (4 articles: Aranda et al., 2015; Fernández-Alcántara et al., 2016; Graham, Stockinger \& Leder, 2013; Levin et al., 2007) and social and community well-being (2 article: Barbee, 2002; Prag \& Vogel, 2013) have illustrated the application of this technique when working with participants ranging from transsexual individuals to grieving patients, individuals coping with the consequences of Alzehimer disease or stroke. Aranda et al. (2015) have implemented photography as a participatory pedagogic method in the training of nursing students, in order to facilitate their ability to be aware of their own culture and values while attempting to provide culturally competent care (Aranda, De Goeas, Davies, Radcliffe \& Christoforou, 2015). Another example was the elicitation of gender stories among a small group of transsexual individuals (Barbee, 2002). Using the method described by Ziller (1990), the protocol implemented a visual-narrative approach to develop a portrayal of the participants' identity. Specifically, findings indicate that the process of using photographic stimuli in the review of one's gender story did not pathologize their condition, but on the contrary was a way to reflect on their life experience.

In the category of Photo presentation there are also those experiences that have applied the photo-projectives technique (3 articles), which involves the presentation of a set of images the subject chooses from during the therapeutic or counseling session. The underlying assumption is that the photographic stimulus selected by the client elicits powerful emotional reactions that can be used in therapy. The name of this technique (projectives) derives from the belief that the meaning assigned to the picture results from a projective process initiated by the client. Among these articles (Loewenthal, 2015; Loewenthal et al., 2016; Saita et al., 2014) we can list a case study of a younger female patient aimed at evaluating the changes in the terms used in the interaction with the provider after the introduction of the photographic stimulus (Saita et al., 2014). The authors concluded that the use of photographs can modify the way the individual processes emotional information, a conclusion supported by the fact that the verbal production of the patient changed from an exclusive focus on the somatic level (I have an headache) to the recognition of the underlying emotion (I'm sad), while the communication style of the subject remained concrete before and after the consultation (Saita et al., 2014).

\section{What? Intervention models}

As mentioned earlier, three are the theoretical models of intervention identified in the literature: Photo Therapy, Therapeutic Photography, and Photo Art Therapy. When this classification (see Table 2 for a description of the characteristics associated with each model) has been applied to the articles included in the review, 4 contributions were categorized in the Therapeutic Photography group, 11 articles in the Photo Therapy, and no contribution could be classified as Photo Art Therapy. However, according to the opinion of the authors, several among them could be placed in more than one category because some of their characteristics overlapped across models: 3 articles could have been classified either as Therapeutic Photography and Photo Therapy, 2 contributions met the criteria for Photo Therapy and Photo Art Therapy, while 1 manuscript presented elements from both Therapeutic Photography and Photo Art Therap (Table 1).

For the purpose of the present review, articles that clearly belong to a single category highlight well the characteristics of the specific model of intervention, as it is theoretically described in the literature (Tables 1 and 2). For example, the experiences classified as Therapeutic Photography exemplify the use of photography with modalities that are not part of a therapy and which are not delivered necessarily by a certified clinician. Photographic techniques are applied by the subjects themselves (or as an organized group) and are aimed at promoting well-being, reducing social exclusion and change within the community. Photo Therapy is illustrated in contribu-

Table 2. Operationalization of the criteria used to organize the articles by model of intervention (based on Weiser, 1999).

\begin{tabular}{|c|c|c|}
\hline Photo Therapy & Therapeutic Photography & Photo Art Therapy \\
\hline $\begin{array}{l}\text { Therapy practices (use of photography during } \\
\text { therapy or clinical intervention) } \\
\text { Proposed/utilized under the guidance of a } \\
\text { therapist trained in PhotoTherapy techniques } \\
\text { Photos used as symbolic self-constructs and } \\
\text { metaphoric objects } \\
\text { Five PhotoTherapy techniques: } \\
\text { 1. Photos which have been taken or created } \\
\text { by clients } \\
\text { 2. Photos which have been taken of clients by } \\
\text { other people } \\
\text { 3. Clients' Self-portraits } \\
\text { 4. Clients' Family albums and other } \\
\text { photo-biographical collections } \\
\text { 5. Clients' Photo-Projective Interaction }\end{array}$ & $\begin{array}{l}\text { Photographic practices } \\
\text { Self-initiated by the individual/group } \\
\text { No prior training in therapeutic theory } \\
\text { or counselling skills }\end{array}$ & $\begin{array}{l}\text { Therapy practice conducted by a } \\
\text { qualified Art Therapist with training } \\
\text { in art media } \\
\text { PhotoTherapy techniques are learned and } \\
\text { adapted to serve the client } \\
\text { The artwork is created during the session } \\
\text { The aim is to create an artistic/aesthetic } \\
\text { product }\end{array}$ \\
\hline
\end{tabular}


tions that describe the use of photographs through structured and methodologically defined methods (like Photovoice or Self-Portrait) within multiple settings such as hospital units, outpatient care settings, and private practice. These type of interventions have been mostly registered in clinical and health settings, and have been introduced with the goal to enhance patients' adjustment under the guidance of a trained health care professional (including experiences at the social and community level). No article that met our eligibility criteria could be classified solely in the Photo Art Therapy group.

\section{Who? The professional figure delivering the intervention}

Finally, the identity of the professionals delivering these types of programs was investigated. Overall, the articles included in the present literature review revealed that a trained professional is always involved, whose role is to contribute to the participant's ability to elaborate and make meaning of the process of using photographic methods. These professionals are not only limited to psychologists and psychotherapists, but also nurses, medical doctors, social workers, sociologists, and teachers are listed as faciltators. This variety indicates also high variability in the type of training and preparation received in the theraputic use of the photographic stimuli.

\section{Discussion}

The application of photographic techniques for therapeutic and clinical purposes has been growing significantly in recent years (Loewenthal, 2013), and the contributions included in this review offer the opportunity to make interesting considerations about the current application of this method in psychosocial settings. The qualitative synthesis conducted in the current article has focused on studies pusblished in the last fifteen years with the ultimate goal to summarize the available literature around contexts of application, methods, models of intervention, and the professional figures involved in the delivery of these kinds of interventions.

From the literature presented, it emerges that photographic methods are implemented mainly in three contexts: physical health, mental health, and social and community well-being. The acquisition of greater selfawareness about the individual's emotional experience represents a general purpose, shared in each context, although the method (what, when, and why) chosen is shaped both by the setting and the specific goals of the intervention. So photos can be used as an instrument to explore the life experiences of participants or they become a medium through which subjects with cognitive, emotional, and linguistic difficulties can share their emotions. An aim, which characterizes intervention modalities used in social and community settings, is to promote the integration of socially marginalized groups.
Three are the methods most commonly utilized in the contributions we have included in this article: Photovoice, Photographic Self-Portrait, and Photo Presentation. Photovoice and Self-Portraits appeared to be implemented mostly in health settings. Specifically, Photovoice was applied with the goal to sensitize the larger social context and the community to the life experience of individuals from minority and underserved groups, while Self-Portraits are integrated to facilitate the emotional processing of the experience. Overall, these two methods enhanced the identification and expression of emotions among members of a marginalized group or individuals with a psychological disorder or a serious illness. Differently, as highlighted by the heterogeneity of settings where Photo Presentation has been implemented, this method appears to be flexible and easy to adapt to the aims of the intervention and the needs of different groups. Within this category we have also identified photo-projectives in clinical and social settings, where the image chosen by the participants during the session is used to mirror their projective process.

Despite the clear theoretical distinction between Photo Therapy, Therapeutic Photography and Photo Art Therapy, this review suggests that in practice it is not always possible to classify interventions and experiences within these three categories. In this sense, the use of photographic techniques, although it cannot exists without a theoretical framework, appears to be characterized by a stronger attention towards a methodological process rather than on the adherence to a single theoretical perspective. While focusing on theory requires to pay attention to theoretical frameworks and constructs (either at the general or micro level based on the reliance on macro or micro theories), by concentrating on the method it is possible to contribute to the development of a path that enhances change and transformation. The method then shapes the intervention, as it implies that the investigators in evaluating the inclusion of photographs in the work with the client take a large number of decisions.

Finally, the last consideration refers to the professional identity of those who deliver the interventions reviewed. Since the focus of these experiences is to increase selfawareness and self-expression, this process must be facilitated by a trained professional. Hence, psychologists, mental health, social, and educational professionals are involved and they are often supported by a photographer. However, we find important to comment on the fact that a great variety of professionals lead these interventions, leaving unclear what are the requirements and the trainings necessary to conduct clinical work. For a review of the debate it is possible to consider Springham, Dunne, Noyse, \& Swearingen (2012).

\section{Conclusions}

Summarizing, the utilization of the photographic stimulus has been consistently associated with improvements 
of emotional, cognitive, and expressive abilities at the individual, group, or community level. Empirical evidence confirms how images can activate and facilitate the communication of thoughts and emotions without the limitation of verbal language, which then contributes to overcome challenges or difficulties some individuals may experience (Uhrig et al., 2016). However, the most relevant finding from this work is that the use of photographs in psychosocial settings cannot be clearly linked to a single model, rather a variety of instruments and techniques have been applied in the current literature.

Some limitations affect the present work. First, the current review is only partially able to address the complexity of some issues still open within the scientific debate. Furthermore, it is possible that some other interventions were not included because authors used different keywords to describe their work, or because of the terminology used to disseminate their experience. Also, articles published in different venues may have been excluded. So, despite its increasing use as an intervention methodology, not many scientific papers concerning the clinical and therapeutic use of photography are currently present in the literature.

Given these limitations, this literature review has contributed to clarify emerging issues at the core of the contemporary debate about this topic, making a distinction between the ideal rules and the actual and current use of photography in psychosocial settings.

The application of photographs is based on the idea that visual media facilitate the access to symbols and unconscious materials (Kopytin, 2006; Weiser, 2014b). Furthermore, since it has been argued that the photographic stimulus might facilitate the re-integration and adaptive reconstruction of emotional elements defensively dissociated from the subjective experience (Wolf, 2007), photographs can therefore serve as a way to promote the unitary and coherent narrative of one's life story. In particular, photographs have the potential to lead to a visual representation of the subject's mental images and internal symbols, thus evoking painful and inaccessible memories, which can then be reassembled and given new meaning in the here and now of the intervention (Halkola, 2009).

\section{References}

American Art Therapy Association (2016). About art therapy. Available from: arttherapy.org.

Aranda, K., De Goeas, S., Davies, S., Radcliffe, M., \& Christoforou, A. (2015). Let's go outside: using photography to explore values and culture in mental health nursing. Journal of Psychiatric and Mental Health Nursing, 22, 306-315. doi:10.1111/jpm.12201

Aubeeluck, A., \& Buchanan, H. (2006). Capturing the Huntington's disease spousal carer experience. Dementia, 5, 95-116. doi: $10.1177 / 1471301206059757$

Barbee, M. (2002). A visual-narrative approach to understanding transsexual identity. Art Therapy: Journal of the American
Art Therapy Association, 19, 53-62. doi: 10.1080/07421656. 2002.10129339

Booth, T., \& Booth, W. (2003). In the Frame: Photovoice and mothers with learning difficulties. Disability \& Society, 18, 431-442. doi: 10.1080/0968759032000080986

Entin, A.D. (1981). The use of photographs and family albums in family therapy. In A. Gurman (Ed.), Questions and answers in the practice of family therapy (pp. 421-425). New York, NY: Brunner-Mazel.

DeCoster, V. A., \& Dickerson, J. (2014). The therapeutic use of photography in clinical social work: Evidence-based best practices. Social Work in Mental Health, 12, 1-19.

Fernández-Alcántara, M., Cruz-Quintana, F., Pérez-Marfil, M. N., Catena-Martínez, A., Pérez-García, M., \& Turnbull, O. H. (2016). Assessment of Emotional Experience and Emotional Recognition in Complicated Grief. Frontiers Psychology, 7, 126. doi: 10.3389/fpsyg.2016.00126

Frith, H., \& Harcourt, D. (2007). Using photographs to capture women's experiences of chemotherapy: reflecting on the method. Qualitative Health Research, 17, 1340-1350. doi: 10.1177/1049732307308949

Glover-Graf, N. M., \& Miller, E. (2006). The use of phototherapy in group treatment for persons who are chemically dependent. Rehabilitation Counseling Bulletin, 49, 166-181. doi: $10.1177 / 00343552060490030401$

Graham, D. J., Stockinger, S., \& Leder, H. (2013). An island of stability: art images and natural scenes-but not natural facesshow consistent esthetic response in Alzheimer's-related dementia. Frontiers in Psychology, 4, 107. doi: 10.3389/fpsyg. 2013.00107

Halkola, U. (2009). A photograph as a therapeutic experience. European Journal of Psychotherapy \& Counselling, 11, 2133. doi: 10.1080/13642530902723116

Halkola U. (2013). A photograph as a therapeutic experience. In D. Lowenthal (Ed.), Phototherapy and Therapeutic Photography in a digital age (pp. 21-33). New York, NY: Routledge.

Hanieh, E., \& Walker, B. M. (2007). Photography as a measure of constricted construing the experience of depression through a camera. Journal of Constructivist Psychology, 20, 183-200. doi: 10.1080/10720530601074739

Karlsson, H. (2013). Phototherapy and neuroscience: Marriage, cohabitation or divorce. In D. Loewenthal (Ed.) Phototherapy and therapeutic photography in a digital age (pp. 159165). New York, NY: Routledge.

Kopytin, A. (2006). Phototherapy: The use of photography in psychological practice. Moscow: Cogito-Center.

Krauss, D. A. (1979). The uses of still photography in counseling and therapy: Development of a training model. Unpublished doctoral dissertation, Kent State University, Kent, Ohio, US.

Levin, T., Scott, B. M., Borders, B., Hart, K., Lee, J., \& Decanini, A. (2007). Aphasia Talks: photography as a means of communication, self-expression, and empowerment in persons with aphasia. Topics in Stroke Rehabilitation, 14, 72-84. doi: 10.1310/tsr1401-72

Loewenthal, D. (2009). Editorial. European Journal of Psychotherapy \& Counselling, 11, 1-6. doi: 10.1080/ 13642530902745804

Loewenthal, D. (2013). Introducing phototherapy and therapeutic photography in a digital age, in: Loewenthal, D. (Ed.) Phototherapy and therapeutic photography in a digital age (pp. 5-20). London, Routledge.

Loewenthal, D. (2015). The therapeutic use of photographs in the United Kingdom criminal justice system. European 
Journal for Psychotherapy and Counselling, 17, 39-56. doi: 10.1080/13642537.2015.1006132.

Loewenthal, D., Avdi, E., Chauhan, G., Saita, E., Natri, T., Righi, R., Tompea, A., Giordmaina, J., \& Issari, P. (2016). Evaluating the therapeutic use of photocards in European prisons. Counselling Psychology Quarterly. doi:10.1080/09515070. 2016.1154018.

Nuñez, C. (2009). The self portrait, a powerful tool for self-therapy. European Journal of Psychotherapy \& Counselling, 11(1), 51-61. doi: 10.1080/13642530902723157.

Pickin, L., Brunsden, V., \& Hill, L. (2011). Exploring the emotional experiences of foster carers using the Photovoice technique. Adoption \& Fostering, 35 (2), 61-75. doi:10.1177/ 030857591103500207.

Phototheraphy and Therapeutic Photography, (2009). European Journal of Psychotherapy \& Counselling, 11.

Prag, H., \& Vogel, G. (2013). Therapeutic photography: fostering posttraumatic growth in Shan adolescent refugees in northern Thailand. Intervention of Mental Health and Psychosocial Support in Conflict Affected Areas, 11, 37-51. doi: 10.1097/WTF.0b013e32835e82f8

Rhodes, S. D., Hergenrather, K. C., \& Wilkin, A. M. (2008). Visions and Voices: indigent persons living with HIV in the Southern United States use Photovoice to create knowledge, develop partnerships, and take action. Health Promotion Practice, 9, 159-169. doi:10.1177/1524839906293829

Saita E., Parrella C., Facchin F., \& Irtelli F. (2014). The clinical use of photography: a single case, multimethod study of the therapeutic process. Research in Psychotherapy: Psychopathology, Process and Outcome, 17, 1-8.

Shamseer, L., Moher, D., Clarke, M., Ghersi, D., Liberati, A., Petticrew, M., Shekelle, P., Stewart, L.A., \& PRISMA-P Group (2015). Preferred reporting items for systematic review and meta-analysis protocols (PRISMA-P) 2015: Elaboration and explanation. BMJ, 349, g7647. doi: 10.1136/ bmj.g7647.

Sitvast, J. E., \& Abma, T. A. (2012). The Photo-instrument as a health care intervention. Health Care Analysis, 20, 77-195. doi: 10.1007/s10728-011-0176-x.

Spence, J. (1986). Putting myself in the picture: a political, personal and photographic autobiography. London: Camden Press.

Springham, N., Dunne, K., Noyse, S., \& Swearingen, K. (2012). Art therapy for personality disorder: 2012 UK professional consensus guidelines, development process and outcome. International Journal of Art Therapy, 17, 130-134.

Stegenga, K., \& Burks, L. M. (2013). Using Photovoice to explore the unique life perspective of youth with sikle cell disease: a pilot study. Journal of Pediatric Oncology Nursing, 30, 269-274. doi: 10.1177/1043454213493508

Stewart, D. (1979). Photo therapy: Theory and practice. Art Psychotherapy, 6, 41-46. doi: 10.1016/0090-9092(79)90019-X
Stewart, D. (1983). Photo therapy: Looking into the Hisstory of Photography. In Krauss D.A., \& Fryrear J.L., Phototherapy in Mental Health (pp. 25-39). Springfield, IL: Charles C. Thomas Publisher.

Thompson, N. C., Hunter, E. E., \& Murray, L. (2008). The Experience of living with chronic mental illness: a Photovoice study. Perspectives in Psychiatric Care, 44, 14-24. doi: 10.1111/j.1744-6163.2008.00143.x

Uhrig, M.K., Trautmann, N., Baumgärtner, U., Treede, R.-D., Henrich, F., Hiller, W., \& Marschall S (2016). Emotion elicitation: A comparison of pictures and films. Frontiers in Psychology, 7, 180. doi: 10.3389/fpsyg.2016.00180

Walker, J. (1982). The photograph as a catalyst in psychotherapy. Canadian Journal of Psychiatry, 27, 450-454.

Walker, J. (1983). The photograph as a catalyst in psychotherapy. In D.A. Krauss, \& J.L. Fryrear (Eds.), Phototherapy in mental health (pp. 135-150). Springfield, IL: Charles C. Thomas Publisher.

Wang, C., \& Burris, M. A. (1994). Empowerment through photo-novella: Portraits of participation. Health Education Quarterly, 21, 171-186.

Weiser, J. (1975). PhotoTherapy: Photography as a verb. The B. C. Photographer, 2, 33-36.

Weiser, J. (1983). Using photographs in therapy with people who are 'different'. In D.A. Krauss \& J.L. Fryer (Eds.), Phototherapy in mental health (pp. 174-199). Springfield, IL: Charles C. Thomas Publisher.

Weiser, J. (1999). Phototherapy techniques: Exploring the secrets of personal snapshot and family albums. Vancouver, BC: PhotoTherapy Centre.

Weiser, J. (2004). PhotoTherapy techniques in counseling and therapy: using ordinary snapshots and photo-interactions to help clients heal their lives. The Canadian Art Therapy Association Journal, 17, 23-53.

Weiser, J. (2014). Establishing the framework for using photos in art therapy (and other therapies) practices. Arteterapia: Papeles de arteterapia y educación artística para la inclusión social, 9, 159-190. doi: 10.5209/revARTE.2014.v9.47490

Weiser, J., \& Krauss, D. (2009). Picturing Phototherapy and Therapeutic Photography: commentary on articles arising from the 2008 international conference in Finland. European Journal of Psychotherapy and Counselling, 11, 77-99. doi: 10.1080/13642530902745820

Wolf, R.I. (1976). The Polaroid technique: Spontaneous dialogues from the unconscious. Art Psychotherapy, 3, 197201. doi: 10.1016/0090-9092(76)90025-9

Wolf, R.I. (1978). The use of instant photography in creative expressive therapy: An integrative case study. Art Psychotherapy, 5, 81-91. doi: 10.1016/0090-9092(78)90012-1

Wolf, R.I. (2007). Advances in phototherapy training. The Arts in Psychotherapy, 34, 124-133. doi: 10.1016/J.aip.2006.11.00 